\title{
Patrimonio cultural y competencias sociales: bases para una propuesta de intervención didáctica en Portomarín
}

\section{Cultural heritage and historical competences: foundations for a proposal of didactic intervention in Portomarín}

\author{
Belén Ma Castro Fernández ${ }^{1}$ \\ belen.castro@usc.es \\ RAMÓN LÓPEZ FACAL \\ ramon.facal@usc.es \\ Universidad de Santiago de Compostela, España
}

\section{Resumen:}

El patrimonio cultural es aquello con lo que las personas se identifican y construyen un sentimiento de pertenencia territorial y caracterización social frente a los demás. Dado que la educación patrimonial en contexto no formal permite el desarrollo de competencias sociales, como es la construcción de una identidad inclusiva, la investigación que se presenta pretende sentar las bases para el diseño futuro de una propuesta didáctica que anime a la participación social y sensibilización de quienes residen y visitan Portomarín (Lugo): un pueblo de origen medieval situado en el Camino de Santiago desparecido bajo las aguas de un embalse inaugurado por Franco en 1963. Comprender lo construido y lo inmaterial, lo presente y lo olvidado, lo marginal y lo destacado en

\begin{abstract}
:
Cultural heritage is what people identify with and with what people build a sense of territorial belonging and social characterization in front of others. Given that patrimonial education in a non formal context allows for the development of social competences, such as the construction of inclusive forms of identity, this study intends to lay the theoretical and methodological foundation for the future design of a didactic proposal that encourages social participation and awareness of those who live in and visit Portomarín (Lugo): a Medieval village in The Way of Saint James which disappeared under the waters of a reservoir, inaugurated by Franco in 1963. Understanding buildings and immaterial heritage, the present and the forgotten, the marginal and the outstanding in new Por-
\end{abstract}

1 Dirección para correspondencia (correspondence address):

Belén $\mathrm{M}^{\mathrm{a}}$ Castro Fernández. Departamento de Didácticas Aplicadas. Área de Didáctica das Ciencias Sociais. Facultad de Educación - Campus Norte. Universidad de Santiago de Compostela. Av. Xoán XXIII s/n. 15782 Santiago de Compostela (España). 
Patrimonio cultural y competencias sociales: bases para una propuesta de intervención didáctica en Portomarín

Belén Ma Castro Fernández y RAMÓN LópeZ faCAL

el nuevo Portomarín, permite demostrar el rol de la educación en la recuperación de la memoria. Se ha diseñado una intervención didáctica dirigida a los habitantes actuales de Portomarín y a los visitantes que ignoran que el pueblo por el que pasan fue trasladado y poco tiene que ver con el antiguo. A partir de este conocimiento se pretende favorecer la construcción de una identidad compartida entre el vecindario, incorporando junto a los restos históricos la memoria del proceso.

\section{Palabras clave:}

Competencias sociales; educación patrimonial; identidad; memoria; Camino de Santiago; Portomarín. tomarín, demonstrates the role of education in the recovery of memory. A didactic intervention was designed aiming to let inhabitants of Portomarín and visitors know that the village they live in was moved from its original location and it has very little to do with the old one. This knowledge seeks to facilitate the construction of a form of identity involving the whole neighborhood together with the historical archeological remains and the memory of the process.

\section{Key words:}

Social competences; heritage education; identity; memory; the Way of Saint James; Portomarín.

\section{Résumé:}

Le patrimoine culturel comporte tout cela avec quoi les gens s'identifient et construisent un sentiment d'appartenance territoriale et de caractérisation sociale face aux autres. Étant donné que l'éducation du patrimoine dans un contexte non formel permet le développement de compétences sociales, telles que la construction d'une identité inclusive, la recherche présentée vise à établir les bases pour la conception futur d'une proposition didactique qui soit capable de promouvoir la participation sociale et la sensibilisation de ceux qui habitent et ceux qui visitent Portomarín (Lugo): un village médiéval au sein du Chemin de Saint-Jacques disparu sous les eaux d'un réservoir inauguré par Franco en 1963. Comprendre ce qui a été construit et l'immatériel, ce qui est présent et ce qui a été oublié, le marginal et l'exceptionnel au sein du nouveau Portomarín, permet de montrer le rôle de l'éducation en ce qui concerne la récupération de la mémoire. On a dessiné une démarche didactique dirigée aux habitants actuels de Portomarín et aux visiteurs qui ignorent que le village qu'ils traversent fut transféré et a peu à voir avec I'ancien. À partir de cette connaissance on essaie de favoriser la construction d'une identité partagée parmi les voisins, intégrant les vestiges historiques et la mémoire du processus.

\section{Mots clés:}

Compétences sociales; éducation du patrimoine; identité; mémoire; Chemin de SaintJacques; Portomarín.

Fecha de recepción: 2-10-2017

Fecha de aceptación: 11-12-2017

\section{Introducción}

La educación patrimonial no se ocupa, solamente, del elemento singular, sino que incluye al resto de bienes que lo acompañan, los lugares y espacios donde se encuentra y a las personas que lo rodean y con las cuales convive. El entorno se convierte en objeto de estudio que debe 
ser examinado y analizado. La base para su comprensión y disfrute se encuentra en su conocimiento, investigación y difusión.

Se debe potenciar una educación que conduzca a construir valores identitarios y a formar una ciudadanía socioculturalmente comprometida (Cuenca, 2014) que haga posible que el respeto por la cultura sea asumido por un amplio sector de la sociedad.

El término patrimonio cultural suele cubrirse de tópicos y consideraciones que simplifican su naturaleza. Es todavía muy frecuente confundir patrimonio y objeto de valor u objeto antiguo. Se tiende a pensar que el patrimonio son aquellas piezas materiales que valen mucho, sin reflexionar siquiera sobre ese valor. La educación patrimonial está en proceso de cambio y reformulación gracias a experiencias de innovación educativa que inciden en el componente humano (Castro y López, 2017).

El patrimonio admite múltiples visiones que mutan dependiendo del ámbito desde el que se proyecten. Las más comunes son la histórica, social, política, económica y turística, sin embargo, deben reivindicarse otras como la identitaria, la emocional y la simbólica, en tanto se refieren a las relaciones entre los elementos patrimoniales y las personas en términos de identificación, propiedad, pertenencia y emoción (Fontal, 2013).

A pesar de ciertas resistencias, cada vez es más habitual su adopción consciente por la sociedad, siempre que se le ofrezcan claves de cómo destacar unos elementos sobre otros. Para evitar discursos ideológico-políticos que puedan desencadenar procesos de desvinculación y despatrimonialización (Llonch, 2015), es necesario que las personas desarrollen procedimientos que les ayuden a empatizar con aquellos referentes culturales de los que exista un enlace, una relación afectiva o un vínculo que se quiera conservar. La configuración de identidades individuales, colectivas y sociales se debería fundamentar en las dimensiones cognitiva y emotiva del patrimonio cultural. El proceso de identificarse con otras personas y lugares implica empatía, una dimensión emocional. Pero la emoción debe complementarse con la racionalidad del conocimiento que proporciona la educación, necesaria para formar personas socialmente competentes.

Lo patrimonial es una cualidad añadida por las personas y por tanto sujeta a cambios en las percepciones y el comportamiento humano (Cuenca, 2014). Esto conduce a cuestionar el discurso oficial. Las identidades están condicionadas por el paso del tiempo y los procesos sociales, por tanto, están en permanente estado de transformación (Do- 
mínguez y López, 2015). Desarrollar la educación patrimonial a través de la sensibilización y la emoción es una forma de promover el interés por conocer, por saber más. No se valora lo que no se conoce.

Los valores que se atribuyen al patrimonio son cambiantes. Sobre un mismo bien se pueden proyectar diferentes tipos (Fontal, 2003); son fundamentales los rememorativos, conmemorativos y de contemporaneidad (Riegl, 1987). Ciertas estrategias didácticas orientadas al público en general pueden contribuir de forma notable a la valoración y comprensión del patrimonio como referente de identidad cultural. Fomentar el respeto y reconocimiento de su rentabilidad social (Ministerio de Educación, 2015), creando vínculos de integración cultural con el entorno, puede sumar interés hacia su potencial para el desarrollo local.

El franquismo alteró considerablemente la vida de muchas personas y sus recuerdos. Ha dejado heridas y memorias sesgadas a cambio de rentabilidad política. Años después se debe intentar superar el trauma produciendo una importante reelaboración de la historia de muchos lugares. Uno de ellos es Portomarín (Lugo), anegado por las aguas del embalse de Belesar en los años sesenta y reconstruido en una cota más elevada, sin mucho que ver con el pueblo antiguo al que trasladaron algunas construcciones singulares.

La educación puede ayudar a superar el desarraigo mediante la construcción de una identidad compartida entre sus habitantes, incorporando, junto a los restos históricos conservados, la memoria del proceso del traslado. En este contexto no formal, también puede ofrecer a los visitantes información que les ayude a comprender este patrimonio con una mirada informada. Se trata de diseñar propuestas que contribuyan a combatir la impunidad del abuso dictatorial y a recuperar la autoestima asociando la historia al presente.

La educación puede proporcionar al vecindario de Portomarín herramientas que le ayuden acomprender su presente y decidir con qué se sensibilizan, se emocionan y qué quieren conservar, más allá de la nostalgia. La mirada hacia el pasado, en este caso no muy remoto, es fundamental. La instrumentalización ideológica que rodea al hundimiento del viejo núcleo medieval y a la nueva ordenación urbana debe ser explicada y comprendida. La sociedad tiene derecho a pensar de manera libre, autónoma y crítica. Necesita instrumentos y procedimientos para estimular su juicio argumentado sobre cómo se reconocen y cómo quieren ser reconocidos. 


\section{Educación patrimonial para formar personas socialmente competentes}

La educación patrimonial es una disciplina de reciente creación. Su presencia en museos, exposiciones incluso centros de interpretación aún es limitada y exige una renovación metodológica. Partiendo de este objetivo transformador, se va conformando un nuevo modelo de actuación que combina los tres ejes vertebradores de la conceptualización patrimonial: memoria, identidad y comunidad (Sánchez, 2016). En este sentido, el reconocimiento de los vínculos emocionales entre las personas, es un pilar fundamental para construir un patrimonio común que conecta pasado, presente y futuro.

Se debe destacar, en primer lugar, la polaridad estética (emocional) e histórica del patrimonio; la idea de que el patrimonio es una expresión ideológica atemporal, puesto que en él es posible condensar su desarroIlo histórico, desde su creación hasta la recepción en el presente (Prats, 2001). En cierto modo, esta visión remite a Crono, el que todo lo devora. La mitología cuenta que Crono engulle a sus propios descendientes según iban naciendo por temor a la profecía de ser destronado por uno de ellos. Temporalidad y eternidad. Dimensiones que entroncan con la frase lapidaria de que el patrimonio no se hereda, se crea. Una expresión que aún descontextualizada adquiere sentido, porque entiende que el patrimonio es la referencia estable que el ser humano busca y posee en un momento concreto, frente a la volatilidad del mundo líquido y global del presente. El patrimonio está en constante cambio; se revisa, valora, define y acepta siguiendo una dinámica espiral. De manera progresiva, el ser humano aplica una mirada crítica, incluso clínica, que permite desarmar y disociar los valores con los que lo patrimonial se ha construido en otra época.

El patrimonio no es sólo cosa de técnicos, debe orientarse a que la ciudadanía participe y sea la protagonista de su patrimonio. Debe contribuir a desarrollar la capacidad de articular entre sí y con su contexto, por la mediación de herramientas didácticas, la manera de comprender, valorar, conservar y transmitir los elementos simbolizados e indisolubles de su pertenencia humana (Castro, 2016).

La mitología ofrece otra referencia a tener en cuenta: Ío, la doncella de Argos que por su relación con Zeus padece, por castigo de Hera, el picoteo continuo de un tábano, el aguijón de la conciencia. En ocasio- 
nes el ser humano rehúsa de su voz interior, del remordimiento por lo no cumplido. A este sufrimiento se puede llegar también por no entender y atender adecuadamente aquello que es legado.

El control rígido del aparato burocrático deshumaniza a la sociedad y la gente pierde su identidad personal y su responsabilidad colectiva. Aunque Pepito Grillo resulte ser un pelmazo para Fernando Savater (1991), la expropiación de la conciencia supone la muerte. Hay que despertar la conciencia crítica y democrática, la capacidad de poder participar en la (re)construcción de la identidad, adquiriendo habilidades y competencias tanto sociales como cívicas. Ser competente supone interpretar el medio en el que se interactúa y proponer alternativas razonadas (López, 2013).

¿Cómo explicar el efecto traumático ejercido por la carencia de un discurso científicamente argumentado? Para entenderlo, hay que precisar una tercera idea: de qué manera el patrimonio oficial, el decidido por los poderes públicos y no siempre bien contextualizado, ha implicado y ha comprometido, tradicionalmente, la historia del ser humano. En otros términos, la necesidad de intervenir didácticamente en los Ilamados patrimonios incómodos; repertorios patrimoniales no asumidos socialmente que cumplen con los requisitos de legitimación para su puesta en valor.

Es fácil afirmar con la palabra y negar con el corazón. Es tan común la hipocresía, actuar de una manera y pensar de otra, que la participación ciudadana se ha debilitado considerablemente en la esfera cultural. Aún más, en asuntos delicados como la memoria que muchas veces son instrumentalizados y manipulados ideológicamente. En el mejor de los casos, la burla y la provocación despiertan preguntas, arrojan voces y descubren identidades ficcionadas.

La hegemonía estatal en la declaración de los bienes culturales implica la imposición de una determinada construcción identitaria, pero las personas libres son capaces de cuestionar un discurso impuesto. La musealización de lugares de memoria o de patrimonios conflictivos para los poderes públicos es una tarea sin fin. Se debe concebir como una labor permanente cuyos resultados no se cifran en el acto mismo de esta adaptación funcional como medio de salvaguarda, que no implica ningún tipo protección efectiva, sino en su valor como paso previo y necesario para la cohesión social, la revisión científica y la difusión didáctica. 
No son los objetos ni la historia los que determinan la identidad; en una sociedad democrática, las personas libres son quienes deben decidir voluntaria y racionalmente identificarse con tradiciones, bienes y valores, y los aprehenden como patrimonio digno de preservar. Desarrollar competencias sociales implica proporcionar los conocimientos de la ciencia y la razón para que libremente asuman y compartan los bienes patrimoniales que consideren pertinentes para construir un futuro mejor.

Entre las múltiples operaciones destinadas a informar sobre un patrimonio incómodo, existen aquellas que inciden más directamente sobre las emociones y sobre su experimentación por la gente. De las historias de vida, a las represiones, pasando por las expropiaciones y las humillaciones, la valorización del patrimonio cultural presenta múltiples formas, de contornos imprecisos, que a menudo se confunden y se asocian; que puede unir el placer estético de bienes materiales con la memoria del sufrimiento de víctimas y perdedores de la historia.

\section{La profanación de un lugar jacobeo: Portomarín}

Los sistemas totalitarios dejan huella tanto el patrimonio como en las relaciones sociales que se establecen con él (Rojo et al., 2014). Numerosas propuestas didácticas sobre la España del siglo XX se ocupan de la guerra civil frente a las que toman a la dictadura franquista como objeto de conocimiento (Hernández y Rojo, 2012). Los restos arqueopatrimoniales de la guerra son más sugerentes por visibles y poseen más capacidad para resultar atractivos en los procesos de enseñanza y aprendizaje. Ahora bien, los elementos y espacios patrimoniales asociados al franquismo tienen una potencialidad elevada para el desarrollo didáctico.

Portomarín es un escenario singular en la historia cultural de Galicia. Su posición estratégica en el Camino de Santiago ya se reconoce en las crónicas medievales. Durante el franquismo el Camino asiste a una intensa revitalización comenzando a adquirir cierta dimensión turística. De hecho, en 1962 el gobierno declara al Camino Francés Conjunto Histórico-Artístico, ampliando las intervenciones que hasta ese momento se venían realizando en su traza; desde mejora de transitabilidad y dotación de equipamientos para peregrinos, hasta restauración de recur- 
sos monumentales y ordenación de parajes con huellas singulares de su condición caminera.

En este contexto, el Estado decide construir el embalse de Belesar para el aprovechamiento hidroeléctrico del río Miño. Al proyectar la presa se observa que el aumento del nivel del agua afecta al núcleo medieval de Portomarín, declarado Conjunto Histórico-Artístico en 1946. Para evitar su anegamiento, en 1955 se proyecta levantar el Nuevo Portomarín y salvar sus construcciones más destacadas. Las obras se llevan a cabo entre los años 1960 y 1964, bajo supervisión del Servicio de Defensa del Patrimonio Artístico Nacional. La dirección recae en el arquitecto Pons Sorolla (Castro, 2010).

El resultado es en un conjunto muy diferente al núcleo medieval de origen, reproduciendo pautas de composición propias de la etapa franquista. El impacto del traslado en la imagen, el paisaje y la memoria de sus habitantes debe y puede ser ampliamente explicado gracias al numeroso material conservado (Figuras 1, 2 y 3 ).

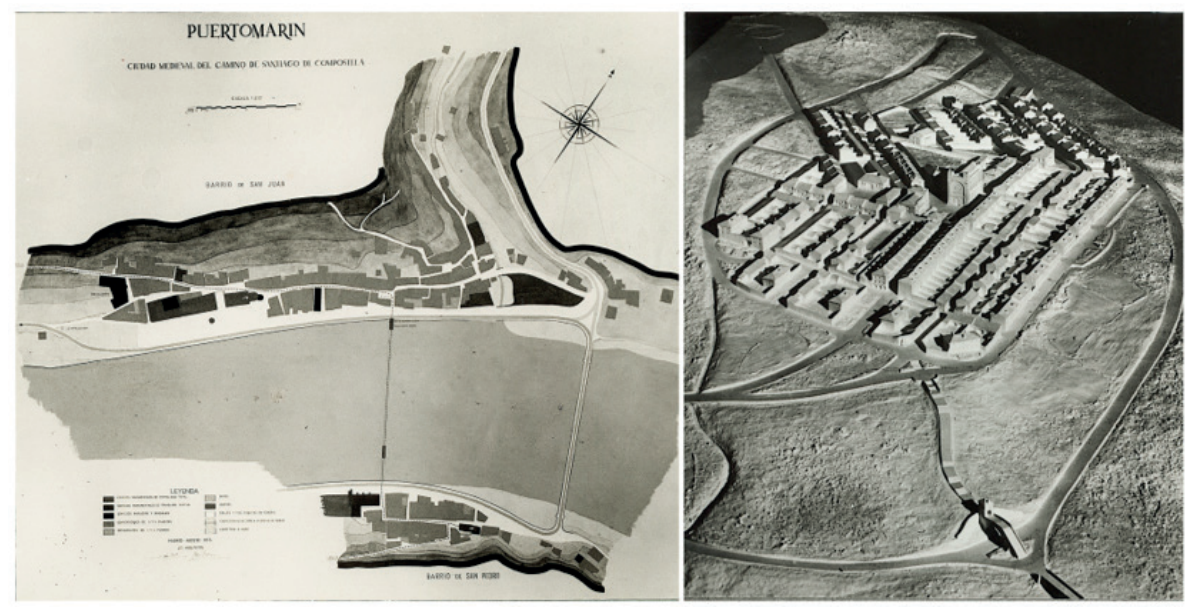

Figura 1. Maquetas del antiguo y nuevo conjunto histórico de Portomarín (Lugo). Fuente: Archivo personal del arquitecto Francisco Pons Sorolla. 


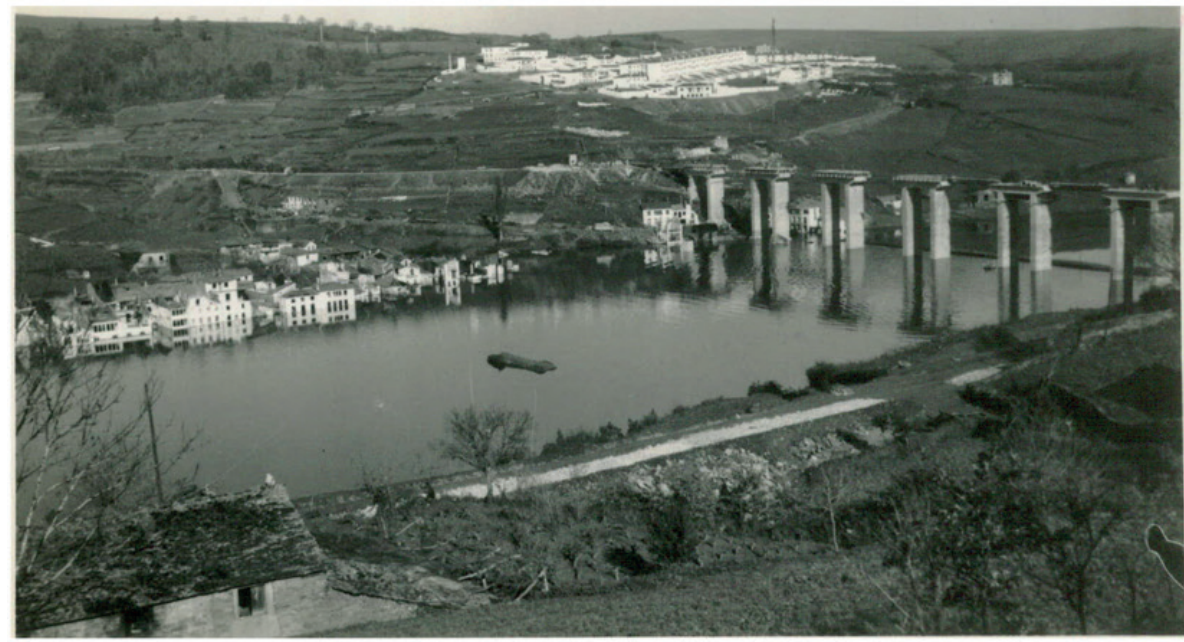

Figura 2. En primer término el viejo conjunto de origen medieval comenzando a ser anegado por las aguas y al fondo el Nuevo Portomarín. Fuente: Archivo personal del arquitecto Francisco Pons Sorolla.
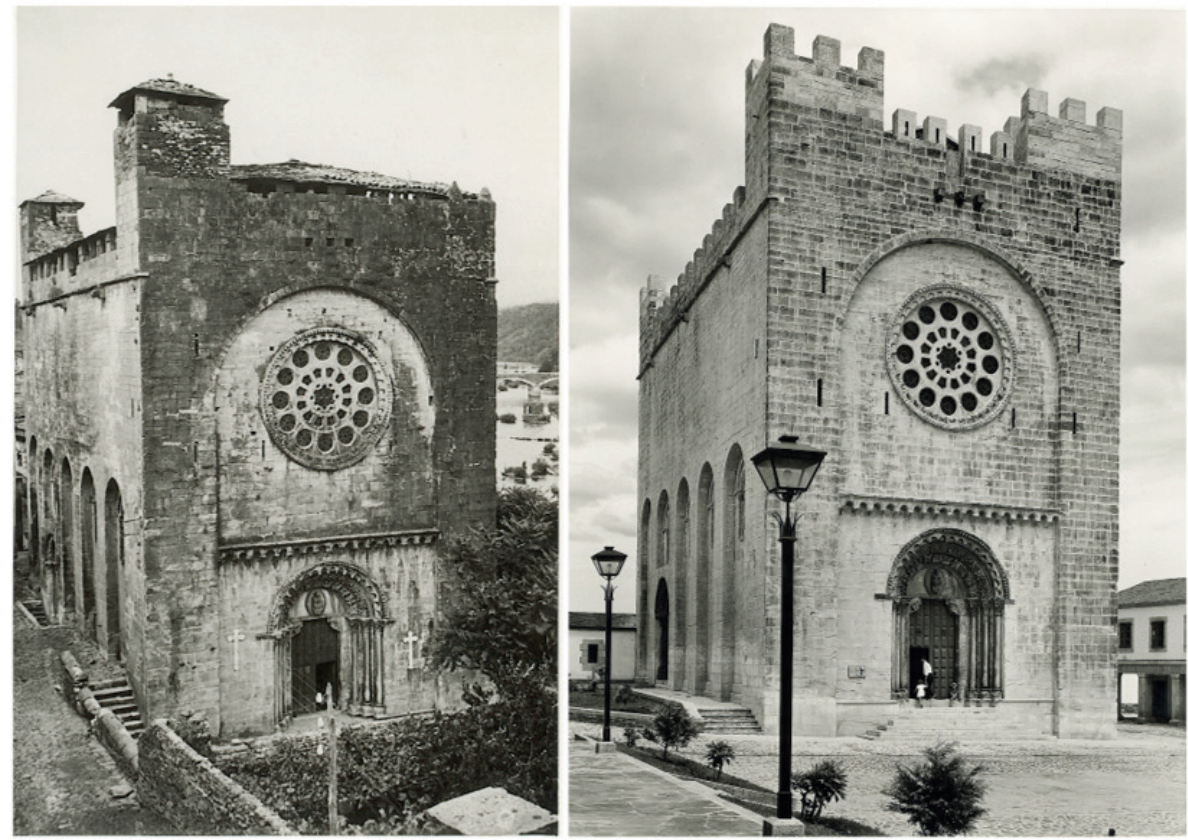

Figura 3. Iglesia de San Xoán antes y después de su traslado. Fuente: Archivo personal del arquitecto Francisco Pons Sorolla. 
Patrimonio cultural y competencias sociales: bases para una propuesta de intervención didáctica en Portomarín

Belén Ma Castro Fernández y Ramón lópez facal

\section{Justificación}

La educación patrimonial va más allá de la dimensión escolar, contribuye a diseñar instrumentos de mediación destinados a la sociedad, para reflexionar sobre como el paisaje pasa de escenario a objeto de conocimiento, a través, por ejemplo, de la memoria como factor de indagación, sacando a la luz historias, personajes o hechos que se hayan ido diluyendo en el tiempo y cuya recuperación permite nuevas lecturas del territorio. Permite, por tanto, descubrir lo invisible en el paisaje del nuevo conjunto.

El vecindario de Portomarín convive con el recuerdo del antiguo núcleo medieval y su conocimiento sobre ambos conjuntos, el antiguo y el moderno, se fragmenta porque habitualmente no sigue alimentándose. No basta con vivir para conocer o recordar. Además, el paso de peregrinos y turistas por el pueblo denota un consumo poco aprovechado de los recursos patrimoniales que éste posee. A los visitantes se les puede ofrecer claves suficientes para que su intercambio cultural con este lugar sea formativo.

La mirada hacia Portomarín debe proyectarse desde la contemporaneidad. Trabajar con el patrimonio pasa por la capacidad de entender no sólo su significado pretérito sino el contemporáneo. Conviene diseñar, por tanto, mecanismos que ayuden a comprender que el patrimonio cultural de Portomarín está vivo y es revisable en su uso y en su significación, en vez de musealizarlo y convertirlo en un "pueblo español" de catálogo, sin fluir ciudadano, que se visita de día y se cierra de noche.

Si la conservación de cualquier conjunto histórico depende en buena parte de la concienciación ciudadana sobre su significación histórica y estética (aprehensión sensorial), parece clara la importancia de aumentar el conocimiento sobre ellas. Por eso, es conveniente que la gestión patrimonial de Portomarín sea integral y tenga en cuenta la acción educadora para reforzar vínculos de pertenencia. En este sentido, el desarroIlo futuro de una intervención didáctica en Portomarín hace necesario no sólo el conocimiento riguroso del patrimonio cultural en cuestión, sino el diagnóstico de los factores de riesgo y el grado de vulnerabilidad que afectan tanto a su conservación como al comportamiento social y urbano que lo rodea. 


\section{Método de investigación}

Actualizar la valoración social del conjunto histórico de Portomarín pasa por mejorar la comunicación de su patrimonio cultural. Crear una acción de difusión, un centro de interpretación o un espacio de comunicación patrimonial dirigido a residentes y visitantes con la doble finalidad de testimoniar su conformación histórica y de interpretar su ambiente desde una perspectiva holística que incluya también elementos emocionales.

El proceso de investigación que ha llevado al planteamiento de esta propuesta se sustenta en el propósito de conectar la emoción con la educación patrimonial para resignificar la historia de Portomarín y construir identidad. Se parte de una tesis doctoral previa realizada en el área de Historia del Arte bajo la óptica de la conservación monumental. La tesis recogió las intervenciones realizadas en conjuntos y arquitecturas históricas de Galicia durante la etapa del franquismo. Uno de los lugares emblemáticos por el alcance y el impacto de la actuación practicada fue Portomarín. En aquel momento se tuvo acceso a numeroso material fotográfico y audiovisual que permitió analizar el cambio que su patrimonio había experimentado en los años sesenta. Faltaba por profundizar en el proceso de exilio forzoso vivido por sus vecinos.

A partir de esa investigación centrada en los objetos se creyó oportuno dar paso a una nueva indagación focalizada en los sujetos, para proporcionar una comprensión del conflicto provocado por el traslado de Portomarín en sus habitantes, tomando como objeto de estudio experiencias, perspectivas e historias personales (Snape y Spencer, 2003).

La dinámica de estudio se organizó en tres fases: concretar teórica y metodológicamente el objeto de estudio; realizar la recogida de datos en torno a la memoria que los vecinos de Portomarín conservan o han desechado de su relación con el territorio natal; y efectuar el análisis de datos y resultados para proponer una acción didáctica a partir de esa memoria recuperada. En este artículo se da cuenta de la primera fase: comprender en profundidad la realidad de estudio penetrando en el contexto local (Somekh, 2010).

Para comprender un fenómeno social no es suficiente la recogida de datos y testimonios; es necesario tener en cuenta el contexto, sus influencias sobre las acciones y el pensamiento que lo impulsa. 
Aplicar lo que Martínez Miguélez (2006) presenta como pensamiento sistémico-ecológico. Los fenómenos sociales, en tanto resultan de una combinación entre lo óntico y lo ontológico de la experiencia vivida (Manen, 2003), se desarrollan en contextos concretos a partir de la construcción que la sociedad hace de la realidad en base a sus interacciones; se trata de una negociación construida socialmente (Berger y Luckman, 1996).

El procedimiento para obtener conocimiento de dicha realidad (información global y contextualizada) comprendió como primer instrumento de recogida de información la observación así como labor heurística. A partir de ahí se empezó a descubrir los significados dados a las cosas por las personas y, lo que es más interesante, determinar una serie de factores significativos que ayudan a caracterizar la relación de los residentes y visitantes de Portomarín con su patrimonio, los problemas y sus causas desde una perspectiva interior o endógena y desde un punto de vista territorial o exógeno. De este modo, se analizaron las debilidades y amenazas que están perjudicando negativamente a esa relación y las fortalezas y oportunidades con las que cuenta. El resultado se resume en un diagrama DAFO (Tabla 1).

Este análisis del contexto permitió plantear una estrategia de mejora de la situación actual, así como diseñar con rigor acciones de difusión y participación ciudadana. Parece razonable que en un lugar de memoria como es Portomarín la acción educadora pase por crear, tal como se viene desarrollando en espacios de esta condición, un centro de interpretación o espacio didáctico donde la gente pueda construir su posicionamiento crítico. El establecimiento de un ambiente expositivo dinámico y participativo pretende facilitar la comprensión, al público en general, de la singularidad de Portomarín en el ámbito cultural, paisajístico y patrimonial de Galicia.

Se parte de varios asuntos fundamentales que son: el carácter jacobeo que ostenta la localidad y que se ha visto territorialmente alterado por el desplazamiento del pueblo; el impacto del traslado en la imagen urbana y el paisaje holístico; la transformación constructiva de los bienes trasladados; la alteración de la memoria patrimonial; el cuestionamiento de la identidad colectiva; y la crítica de autenticidad o falsificación del conjunto histórico. 
Tabla 1. Análisis DAFO para comprender el conjunto histórico de Portomarín (Lugo). Elaboración propia.

\begin{tabular}{|c|c|}
\hline Debilidades & Fortalezas \\
\hline $\begin{array}{l}\text { - Envejecimiento de la población } \\
\text { - Débil identificación ciudadana } \\
\text { con el conjunto histórico } \\
\text { - La historia local no es relevante } \\
\text { para el visitante } \\
\text { - Falta de iniciativas y medidas de } \\
\text { protección del conjunto histórico } \\
\text { (Plan Especial, ARI) }\end{array}$ & $\begin{array}{l}\text { - Situación geográfica: Camino de } \\
\text { Santiago y río Miño } \\
\text { - Clima de convivencia cívica } \\
\text { - Mantenimiento del uso residencial } \\
\text { como uso preferente } \\
\text { - El casco histórico es el centro de la } \\
\text { vida social del municipio }\end{array}$ \\
\hline Amenazas & Oportunidades \\
\hline $\begin{array}{l}\text { - Tradiciones en extinción } \\
\text { - Pérdida de la memoria urbana } \\
\text { - Despoblamiento del conjunto his- } \\
\text { tórico } \\
\text { - Impacto del turismo desinformado } \\
\text { e ignorante de la historia local } \\
\text { - Disminución de presupuestos para } \\
\text { la salvaguarda del conjunto históri- } \\
\text { co } \\
\text { - Riesgo de convertirse en un con- } \\
\text { junto-museo (sin vida y con poca } \\
\text { dinamización) }\end{array}$ & $\begin{array}{l}\text { - Recuperación demográfica } \\
\text { - Promoción del patrimonio y de } \\
\text { una actividad cultural intensa (ba- } \\
\text { sada en la intervención de múlti- } \\
\text { ples agentes) } \\
\text { - Potenciación y valoración del } \\
\text { patrimonio tangible e intangible } \\
\text { como base de una estrategia de de- } \\
\text { sarrollo municipal } \\
\text { - Mejorar la interpretación del con- } \\
\text { junto histórico (educación, forma- } \\
\text { ción e información patrimonial) } \\
\text { - Diseñar proyectos de valoración } \\
\text { del patrimonio } \\
\text { - Utilización de algunos edificios } \\
\text { singulares para acoger usos cen- } \\
\text { trales, como es el caso del antiguo } \\
\text { cine situado en una posición estra- } \\
\text { tégica } \\
\text { - Fortalecer la ciudadanía como pro- } \\
\text { tagonista del conjunto histórico }\end{array}$ \\
\hline
\end{tabular}

El carácter jacobeo es un tema que conviene resaltar por el importante peso que ha tenido en la configuración de este conjunto histórico. Con su hundimiento y traslado parcial fue necesario desviar la traza de la Ruta. La creación del nuevo poblado origina rectificaciones de ramales y nuevas pendientes adaptadas a los anchos de las carreteras. El conocimiento de todas estas vicisitudes ha de sugerir una reflexión crítica sobre si los vecinos rechazan o aceptan la nueva dimensión jacobea de Portomarín. 
Otro asunto de interés como punto de partida es conocer en qué medida el traslado y la nueva construcción del pueblo inciden en la preservación del medio ambiente. El concepto a trabajar en este nivel de análisis es el de la integridad, entendida como la conservación del emplazamiento original (geográfico, arquitectónico, cultural) y disposición de construcciones, y su relación con el medio que les rodea y las caracteriza tipológicamente. El dilema oscila entre los conceptos de cambio y continuidad. De cómo el traslado del pueblo introduce nuevas oportunidades de mejora urbanística a cambio de perder los rasgos connaturales.

La lectura reflexiva de Portomarín en el pasado y en el presente también merece un lugar destacado. En el caso de los bienes protegidos interesa conocer cómo vivieron los vecinos la reconstrucción historicista de sus monumentos trasladados. Este es uno de los problemas con mayor potencialidad educativa: la instrumentalización política que rodea a la construcción del embalse. Las causas y consecuencias de una decisión administrativa que ocasiona el desarraigo de un pueblo entero despiertan el debate y la polémica: ¿hasta qué punto el aprovechamiento hidroeléctrico del río Miño debe prevalecer sobre la conservación de un conjunto declarado histórico-artístico en 1946? ¿cómo aplicar las medidas legales de protección cultural ante un patrimonio en riesgo? ¿qué impacto tiene el traslado en los monumentos declarados?

Otro aspecto fundamental es identificar si existe un proceso de sensibilización y apropiación de los vecinos de Portomarín con respecto al nuevo conjunto. Conocer la memoria, y no únicamente la historia del viejo núcleo, es clave para entender la dimensión humana del patrimonio cultural. Descubrir los recuerdos de las personas, sus tradiciones y costumbres, permite activar los mecanismos necesarios de la emoción en el reconocimiento colectivo del patrimonio. El sujeto empatiza con los recursos culturales no sólo porque sean importantes artísticamente, sino porque se identifica con ellos y porque les reconoce valores que quieren destacar y mantener, ante el riesgo de su pérdida durante el traslado. De este modo, se puede reflexionar sobre la implicación de los vecinos en la conservación y transmisión patrimonial de su pueblo.

Por otra parte, en la función sociocultural de la educación patrimonial confluyen conflictos de intereses. Desde las ciencias sociales se trabajan conceptos, métodos y prácticas que fomentan la convivencia pacífica de la ciudadanía (López y Valls, 2012). También se desarrolla una praxis educativa democrática para que, comprendiendo lo que está 
sucediendo, las personas quieran cambiarlo (Pagès, 1998; Santisteban, 2012). Bajo este prisma, se propone relacionar los hechos con los valores y aprender a pensar dialécticamente.

La dimensión ética del vecino de Portomarín se puede despertar cuando conoce y comprende el impacto patrimonial del traslado. La sociedad tiene derecho a comprender la verdadera evolución de este enclave, todas sus fases, incluso las de nueva ordenación, porque adquieren historicidad en el momento de su ejecución. Hasta este punto se constata que las posibilidades de estudio que ofrece el conjunto de Portomarín son muchas.

Las posibilidades didácticas que ofrece el conjunto de Portomarín son muchas. El planteamiento para el contexto no formal diseñado constituye el cimiento sobre el que se está trabajando (Tabla 2).

Tabla 2. Bases para una propuesta de educación patrimonial en Portomarín. Elaboración propia.

\begin{tabular}{|c|c|c|c|}
\hline & Viejo Portomarín & Traslado & Nuevo Portomarín \\
\hline $\begin{array}{l}\text { Signifi- } \\
\text { cación } \\
\text { histórica }\end{array}$ & $\begin{array}{l}\text { Carácter jacobeo.- } \\
\text { conocer que el } \\
\text { Camino de San- } \\
\text { tiago atravesaba el } \\
\text { antiguo conjunto } \\
\text { histórico }\end{array}$ & $\begin{array}{l}\text { Profanación.- deliberar } \\
\text { sobre la ruptura que el } \\
\text { anegamiento y el trasla- } \\
\text { do ocasionan en el re- } \\
\text { corrido del Camino de } \\
\text { Santiago }\end{array}$ & $\begin{array}{l}\text { Carácter jacobeo.- } \\
\text { promover la re- } \\
\text { flexión sobre la mu- } \\
\text { sealización jacobea } \\
\text { de Portomarín }\end{array}$ \\
\hline $\begin{array}{l}\text { Cambio y } \\
\text { continui- } \\
\text { dad }\end{array}$ & $\begin{array}{l}\text { Imagen urbana y } \\
\text { paisaje.- descubrir } \\
\text { cómo era la per- } \\
\text { sonalidad tortuosa, } \\
\text { irregular y orgá- } \\
\text { nica del antiguo } \\
\text { conjunto histórico }\end{array}$ & $\begin{array}{l}\text { Emplazamiento.- con- } \\
\text { siderar la permanencia } \\
\text { y la pérdida de rasgos } \\
\text { propios (naturales y } \\
\text { construidos) en ambas } \\
\text { ubicaciones }\end{array}$ & $\begin{array}{l}\text { Imagen urbana y } \\
\text { paisaje.- contrastar } \\
\text { la nueva planifica- } \\
\text { ción y su integra- } \\
\text { ción en el entorno } \\
\text { natural }\end{array}$ \\
\hline $\begin{array}{l}\text { Causas y } \\
\text { consecuen- } \\
\text { cias }\end{array}$ & $\begin{array}{l}\text { Bienes protegidos.- } \\
\text { reconocer el valor } \\
\text { histórico-artístico } \\
\text { de los elementos } \\
\text { culturales decla- } \\
\text { rados }\end{array}$ & $\begin{array}{l}\text { Construcción del em- } \\
\text { balse.- razonar la ne- } \\
\text { cesidad de trasladar, al } \\
\text { menos, los bienes cuya } \\
\text { protección debe estar } \\
\text { garantizada legalmente }\end{array}$ & $\begin{array}{l}\text { Bienes protegidos.- } \\
\text { valorar el impacto } \\
\text { del traslado en los } \\
\text { monumentos re- } \\
\text { construidos }\end{array}$ \\
\hline
\end{tabular}




\begin{tabular}{|c|c|c|}
\hline & Viejo Portomarín & Nuevo Portomarín \\
\hline $\begin{array}{l}\text { Sensibi- } \\
\text { lización pa- } \\
\text { trimonial }\end{array}$ & $\begin{array}{l}\text { Memoria.- cono- } \\
\text { cer los recursos } \\
\text { que constituyen } \\
\text { el patrimonio cul- } \\
\text { tural del antiguo } \\
\text { conjunto histórico }\end{array}$ & $\begin{array}{l}\text { Emoción y apropiación.- Memoria.- desarro- } \\
\text { empatizar con el patri- Ilar conocimiento } \\
\text { monio cultural de Por- sobre la interven- } \\
\text { tomarín, se identifica ción de la gente en } \\
\text { con él (construcción de la conservación del } \\
\text { identidad) y le recono- patrimonio cultural } \\
\text { ce valor(es) } \\
\text { de Portomarín }\end{array}$ \\
\hline $\begin{array}{l}\text { Dimensión } \\
\text { ética }\end{array}$ & $\begin{array}{l}\text { Autenticidad his- } \\
\text { tórica.- tomar } \\
\text { contacto con tes- } \\
\text { timonios y fuentes } \\
\text { primarias sobre el } \\
\text { patrimonio cul- } \\
\text { tural del antiguo } \\
\text { conjunto histórico }\end{array}$ & $\begin{array}{l}\text { Falso histórico.- re- } \text { Autenticidad histó- } \\
\text { flexionar sobre la falsi- rica.- adquirir crite- } \\
\text { ficación de los monu- rios ante una situa- } \\
\begin{array}{ll}\text { mentos trasladados ción de conflicto } \\
& \text { similar al traslado } \\
& \text { de Portomarín }\end{array}\end{array}$ \\
\hline
\end{tabular}

\section{Apuntes finales}

El campo de aplicaciones de la educación patrimonial en el conjunto histórico de Portomarín no se limita únicamente a la exégesis de los monumentos reconstruidos y sus alteraciones morfológicas. Puede utilizarse igualmente para análisis relativos a la expropiación y mutilación de la historia propia por imposición política como conflicto ético, que implica conjuntamente a residentes y visitantes.

En la búsqueda de información, cuya meta es la comprensión de la acción humana y los significados que los sujetos construyen sobre lo que les rodea, es conveniente decidir el punto de vista para analizar e interpretar los procesos estudiados, que, en un estudio cualitativo, combinan creencias, percepciones y procesos personales de interpretación (Bisquerra, 2009). Para profundizar en la memoria de Portomarín se ha seleccionado el paradigma interpretativo por su capacidad para contrastar los temas con la realidad evaluando todo el proceso de trabajo.

En la primera fase del proceso de investigación que se ha llevado a cabo la búsqueda de información bibliográfica ha sido clave para definir cada uno de los asuntos más relevantes en la re-significación de la historia contemporánea de Portomarín. Una labor exhaustiva y pormenorizada que, sin embargo, no habrá de condicionar el trabajo de campo en 
tanto que abierto y flexible para detectar la posible aparición de nuevos ítems de estudio. La revisión de este material ha posibilitado, asimismo, justificar la necesidad de afrontar el estudio de esta temática y de este caso concreto.

Los recursos visuales recopilados comportan un papel destacado en la recogida de información, fortaleciendo el proceso de análisis e interpretación (Eisner, 1998). Las fotografías y las filmaciones son importantes porque contribuyen a comprender mejor una realidad que ya no existe, aunque pueden mitificar la memoria de las personas en las imágenes reproducidas, incluso codificar estereotipos y tipismos propios del discurso desetnizador impulsado por el franquismo haciendo ver que el nuevo Portomarín contribuye a satisfacer una necesidad social. Con todo, han sido valiosas porque han permitido arrojar luz para comprobar la idoneidad del tema de estudio.

Esta labor heurística ha puesto de manifiesto la conveniencia de impulsar un centro de interpretación sobre la memoria recuperada de Portomarín para reforzar vínculos de pertenencia y que sirva, además, para despertar preguntas relevantes sobre el pasado y desarrollar conciencia de por qué se da una significación histórica determinada a este enclave. Y, de este modo, contribuir a que los visitantes de este espacio didáctico sean capaces de construir una interpretación propia que les ayude a tomar conciencia de la relevancia patrimonial del lugar, desterrando posibles manipulaciones políticas en la ocultación de episodios clave específicos en la historia local. Contribuir, en suma, a formar personas reflexivas capaces de argumentar.

El juicio sobre la oportunidad y ventajas de este proyecto debe emitirse teniendo en cuenta los siguientes aspectos: la posibilidad de ampliar su alcance a una perspectiva patrimonial global; la reducción de costes progresiva a la hora de atender la interpretación de un territorio potencialmente tan amplio (los dos conjuntos históricos y el Camino de Santiago); la capacidad de actualizar los resultados obtenidos de un modo constante; $y$, sobre todo, la creación de un instrumento tanto para la valoración científica de la dinámica de sensibilización ciudadana (construcción de identidad), como para la toma de decisiones de la administración respecto a la protección del patrimonio cultural de Portomarín. 
Patrimonio cultural y competencias sociales: bases para una propuesta de intervención didáctica en Portomarín

Belén Ma Castro Fernández y Ramón lópeZ facal

\section{Agradecimientos}

Este trabajo forma parte de la investigación financiada por el Plan Nacional de I+D+i del MINECO (EDU2015-65621-C3-1-R) y cofinanciado con fondos FEDER de la UE.

\section{Referencias bibliográficas}

Berger, P. y Luckman, T. (1998). La construcción de la realidad. Buenos Aires: Amorrortu. Bisquerra Alzina, R. (coord.) (2009). Metodología de la investigación educativa. Madrid: La Muralla.

Castro Fernández, B. Ma (2010). El redescubrimiento del Camino de Santiago por Francisco Pons-Sorolla. Santiago de Compostela: S. A. de Xestión do Plan Xacobeo-Xunta de Galicia.

Castro Fernández, B. Ma y López Facal, R. V. (2017). La educación patrimonial servicio de la ciudadanía. En P. Miralles, C. Gómez y R. Rodríguez (Eds.). La enseñanza de la historia en el siglo XXI. Desarrollo y evaluación de competencias históricas para una ciudadanía democrática (pp. 167-188). Murcia: Universidad de Murcia.

Castro Marín, P. De. (2016). Cartografía autoetnográfica de una genealogía de programas de educación patrimonial desde la perspectiva del aprendizaje basado en proyectos y la investigación-acción (Tesis doctoral). Universidad de Valladolid. Facultad de Educación y Trabajo Social. Recuperado de http://uvadoc.uva.es/handle/10324/16853.

Cuenca López, J. M ${ }^{a}$ (2014). El papel del patrimonio en los centros educativos: hacia la socialización patrimonial. Tejuelo, 19, 79-96.

Domínguez Almansa, A. y López Facal, R. (2015). Patrimonio, entorno y procesos de identificación en la educación primaria. CLIO. History and History teaching, 41. Recuperado de http://clio.rediris.es/n41/articulos/mono/MonFacal2015.pdf.

Eisner, E. (1998). El ojo ilustrado. Indagación cualitativa y mejora de la práctica educativa. Barcelona: Paidós.

Fontal Merillas, O. (2003). La educación patrimonial: teoría y práctica para el aula, el museo e Internet. Gijón: Trea.

Fontal Merillas, O. (2013). La educación patrimonial. Del patrimonio a las personas. Gijón: Trea.

Hernández Cardona, F. X. y Rojo Ariza, C. (2012). Arqueología y didáctica del conflicto: el caso de la guerra civil española. Revista de Didácticas Específicas, 6, 159-176.

López Facal, R. (2013). Competencias y enseñanza de las ciencias sociales. Íber. Didáctica de las Ciencias Sociales, Geografía e Historia, 74, 5-8.

López Facal, R. y Valls Montés, R. (2012). La necesidad cívica de saber historia y geografía. En N. Alba, F. García y A. Santisteban (Coords.) Educar para la participación ciudadana en la enseñanza de las Ciencias Sociales(pp. 185-192). Sevilla: Asociación Universitaria de Profesorado de Didáctica de las Ciencias Sociales.

Llonch Molina, N. (2015). La educación patrimonial como herramienta de "rebeldía 
Patrimonio cultural y competencias sociales: bases para una propuesta de intervención didáctica en Portomarín

Belén Ma Castro Fernández y Ramón López faCAL

ciudadana". Educação histórica e educação patrimonial- novos desafíos. En G. Solé (Coord.). II Seminário internacional de educação patrimonial: contributos para a construção de umaconsciência patrimonial (pp. 37-52). Braga: Universidade do Minho, Instituto de Educação.

Manen, M. V. (2003). Investigación educativa y experiencia vivida. Ciencia humana para una pedagogía de la acción y la sensibilidad. Barcelona: Idea Books.

Martínez Migélez, M. (2006). Ciencia y arte en la metodología cualitativa. México: Trillas. Ministerio de Educación, Cultura y Deporte (2015). Plan Nacional de Educación y Patrimonio. Madrid: Secretaría General Técnica, Subdirección General de Documentación y Publicaciones.

Pagès Blanch, J. (1998). Los valores y la didáctica de las Ciencias Sociales: retos para la formación de una conciencia democrática. En Los valores y la didáctica de las ciencias sociales. IX Simposio de Didáctica de las Ciencias Sociales (pp. 7-20). Lleida: Universidad de Lleida, Asociación Universitaria de Profesorado de Didáctica de las Ciencias Sociales.

Prats, J. (2001). Valorar el patrimonio histórico desde la educación: factores para una mejor utilización de los bienes patrimoniales. Aspectos didácticos de las ciencias sociales, 15, 157-171.

Riegl, A. (1987). El culto moderno a los monumentos. Madrid: Visor.

Rojo Ariza Ma C., Cardona GóMez, G., Romero Serra, M., Feliu Torruella, M., Jiménez Torregrosa, L., Íñiguez Gràcia, D., Hernàndez Cardona, F. X. (2014). Patrimonio, conflicto y relevancia histórica. Una experiencia formando a los futuros profesionales de la educación. CLIO. History and History teaching, 40. Recuperado de http://clio. rediris.es/n40/articulos/mono/MonRojoetal2014.pdf.

Sánchez Ferri, A. (2016). Memoria, identidad y comunidad: evaluación de programas de educación patrimonial en la Comunidad de Madrid (Tesis doctoral). Valladolid: Universidad de Valladolid. Facultad de Educación y Trabajo Social.

Santisteban Fernández, A. (2012). La investigación sobre el desarrollo de la competencia social y ciudadana para una participación crítica. En N. Alba, F. García, A. Santisteban (Coords.) Educar para la participación ciudadana en la enseñanza de las Ciencias Sociales(pp. 277-286). Sevilla: Asociación Universitaria de Profesorado de Didáctica de las Ciencias Sociales.

Savater, F. (1991). Ética para Amador. Barcelona: Ariel.

Snape, D. y Spencer, L. (2003). The foundations of qualitative research. En J. Ritchie y J. Lewis (ed.). Qualitative research practice. A guide for social science students and researchers (pp. 1-23). London: Sage.

Somekh, B., Burman, E., Delamont, S., Meyer, J., Payne, M., Thorpe, R. (2010). Research in social sciences. En B. Somekh y C. Lewin (ed.). Theory and methods in social research (pp. 1-14). Los Angeles: Sage. 
